\title{
New Dynamic Plate System Combined with Titanium Mesh Cage and Bone Graft in the Treatment of Cervical Spondylosis
}

\author{
Wenjie WU, Yunbei YANG, Hao LIU, Yin HONG, Quan GONG, Tao LI, Limin LIU, Yueming SONG \\ West China Hospital, Department of Orthopaedics, Chengdu, Sichuan, China
}

\section{ABSTRACT}

AIM: Dynamic plates have been popularized to promote cervical spine fusion. There are no studies comparing the effectiveness and complications between traditional static plates and new dynamic plates (Vectra-T, Synthes, Switzerland).

MATERIAL and METHODS: From June 2009 to October 2012, 70 patients underwent anterior cervical corpectomy and fusion (ACCF) in our hospital for the treatment of cervical spondylosis. Vectra-T plate was used in 36 patients (dynamic group) while traditional static plate was used in 34 patients (static group). Sagittal section angle, sagittal plane mobility, coronal angle of the titanium mesh cage were measured and the change of sedimentation rate was calculated at the postoperative $3^{\text {rd }}, 6^{\text {th }}, 12^{\text {th }}$ months and at the end of follow-up period for each patient. The Japanese Orthopedic Association (JOA) score and local cervical angle were also measured before, immediately after surgery and at the end of follow-up period. These data were compared for both groups.

RESULTS: The follow-up period was between 12 and 38 months. The clinical outcome was similar in both groups based on the JOA score, local cervical angle and regional cervical angle. All patients had good clinical outcome without fracture of the plates or screws. There were no differences between the two groups at the $3^{\text {rd }}, 6^{\text {th }}$ and $12^{\text {th }}$ months after surgery regarding to fusion rate $(p>0.05)$. Settling of the construct and plate migration was similar between the groups at all time points.

CONCLUSION: There was no statistically significant difference between dynamic plates and static plates regarding to fusion rate. The clinical outcomes and radiographic changes were also similar in both groups.

KEYWORDS: Cervical spondylosis, Anterior cervical corpectomy and fusion, Static plate, Dynamic plate, Titanium mesh cage

\section{INTRODUCTION}

$\Lambda$ nterior cervical discectomy and fusion were first reported by Bailey and Badgley (1), Smith and Robinson (31), and Cloward (8) in the 1950s and 1960s. Although there were small differences between the methods $(7,13,29)$, all methods had severe complications such as graft dislodgment, pseudo-arthrosis and kyphotic deformity. In order to prevent these complications, a reinforced plate has been widely used $(3,26)$.

The use of plating systems enhanced fusion rates, improved initial stability, reduced need for re-operation, decreased complications from graft migration, and decreased hospital stays $(21,30,32)$. Nevertheless, the static plates are designed to rigidly immobilize the treated level and to reduce micromotion between the graft-bone interfaces. On the other hand, the rigidity of these plating systems will cause stress shielding across the graft which may in fact adversely affect graft healing according to the Wolff law $(5,6,28)$. The absorption of bone graft will lead to reduce of the vertebral height. Consequently, the integration of bone and the distribution of the force will be affected $(12,24)$.

Recently, dynamic cervical plates have been introduced to solve this problem. Biomechanical studies confirmed that the dynamic plates can reduce the stress shielding by allowing load sharing across the graft construct $(2,9)$ without apparent 
loss of rigidity. Consequently, these plates increased the radiographic fusion rates and reduced the complications secondary to implants.

The hypothesis for dynamic plates is still controversial. Currently, there is no study comparing the outcomes of dynamic and static plating techniques used in anterior cervical corpectomy and fusion (ACCF). The aim of our study was to show the reduction of complication rates in dynamic plates, the fusion rates and speed of dynamic plating, the reduction of cervical lordotic angle and similar or better clinical outcomes regarding to the static plates.

\section{MATERIAL and METHODS}

\section{Materials and Patient Population}

From June 2009 to October 2012, 70 patients, who underwent ACCF for the treatment of cervical spondylosis were included in our study. Vectra-T plate was used in 36 patients and traditional static plate was used in other 34 patients. Among the 70 patients, 27 had cervical spondylotic myelopathy (CSM), 29 had cervical spondylotic radiculopathy (CSR), and 14 patients had mixed cervical spondylosis.

For anterior cervical plating, either a dynamic plate (study group, $n=36$ ), or a constrained, static (rigid) plate (control group, $n=34$ ) was selected for fusion. One level corpectomy was performed in all patients because they had two intervertebral disc involvements. There were 25 male and 11 female patients in the dynamic-plate group, with an average age of $58.1 \pm 10.14$ years (ranged between 44 and 75 years). The duration of the disease was ranged between 1 and 120 months (average 23 months), with a follow-up period between 12 and 36 months. In the static-plate group, there were 21 male and 13 female patients with a mean age of $56.7 \pm 11.06$ years (ranged between 40 and 72 years). The duration of disease was ranged between 1 and 180 months (average 26 months) in the static-plate group and the follow-up period ranged between 12 and 42 months (Table I). Cervical spondylosis was definitely diagnosed in all patients after a detailed history and physical examination.

The exclusion criteria were: Patients with 2 or 3 level corpectomies, previous posterior cervical surgery, bone fusion in adjacent level of the cervical spine, suit for the artificial cervical disc replacement and were prepared for the surgery, severe osteoporosis, severe rheumatoid arthritis, active or suspected infection and malignancy.

\section{Measurement Method}

In order to determine the location, character, the grade of spinal cord injury and the level of surgery, all patients underwent the anteroposterior and lateral plain X-rays, lordotic and kyphotic position X-rays, computed tomography (CT) and magnetic resonance imaging (MRI) examinations before the surgery. Sagittal section angle, sagittal plane mobility and coronal angle of the titanium mesh cage, as well as the changes of sedimentation rate were measured and compared between the two groups at the postoperative $3^{\text {rd }}, 6^{\text {th }}$ and $12^{\text {th }}$ months and at the end of follow-up period (Figures 1, 2). The Japanese
Orthopedic Association (JOA) score, local and regional cervical angles (C3-C7) were measured before, immediately after surgery and at the end of follow-up period.

The speed of bone fusion, the rate of implant-related complications, the effectiveness of surgery and the radiological changes were compared for static-plate and dynamic plate groups.

Solid fusion was defined as the presence of following radiographic features: Absence of lucency or halo formation around the screws or cage-bone interfaces, lack of translation and $<5^{\circ}$ of motion in the flexion-extension radiographs, and osseous continuity through and/or around the cages on the followup sagittal reconstruction CT scans (Figures 3, 4).

The sedimentation rate is defined as the ratio of the height of mesh case and the distance between the mid-point of upper end plate to the mid-point of lower end plate $(14,15)$. The degree of cervical curvature was measured by the Cobb method.

\section{Surgical Technique}

All patients underwent implantation of a cervical plate by anterior approach with complete decompression of the spinal cord. The titanium mesh was trimmed to the needed length and the corpectomy was performed with rongeurs and Kerrison punch leaving only the posterior cortical margins in place. Once the corpectomy had been completed, a titanium mesh cage was inserted with an autologous local bone graft harvested during the corpectomy. Finally, a plate and variable screws were implanted in all patients. The patients were mobilized a day after the surgery and discharged from the hospital at the postoperative $5^{\text {th }}$ to $7^{\text {th }}$ days. Patients used a hard collar for 3 months after discharge and performed appropriate physical exercises.

\section{Statistical Analysis}

Statistical analysis was performed using Chi-square and Mann-Whitney tests. Results were considered statistically significant when $p$ value was less than 0.05 .

Table I: Patient Demographics

\begin{tabular}{lcc}
\hline & \multicolumn{2}{c}{ Number } \\
\hline & Static plate & Dynamic plate \\
\hline Gender & & \\
\hline \multicolumn{1}{c}{ Male } & 21 & 25 \\
\hline$\quad$ Female & 13 & 11 \\
\hline Average age (years) & $56.7 \pm 11.06$ & $58.1 \pm 10.14$ \\
\hline Diagnosis & & \\
\hline$\quad$ Myelopathy & 12 & 15 \\
\hline$\quad$ Radiculopathy & 17 & 12 \\
\hline$\quad$ Mixed & 5 & 9 \\
\hline Course of disease (month) & $1-120$ & $1-180$ \\
\hline Time of follow up & $12-42$ & $12-36$ \\
\hline
\end{tabular}




\section{RESULTS}

Overall, the average time of surgery was 145 minutes and the average amount of bleeding was $50 \pm 0.84 \mathrm{ml}(40 \mathrm{ml}-60 \mathrm{ml})$. Until the end of the follow-up period, there was no patient who experienced neurological deterioration, deep infection or cardiopulmonary insufficiency. There were no surgeryrelated complications such as plate fracture, screw loosening happened after surgery or during the period of follow-up. All of the 70 patients showed clinical improvement and solid bony fusion without pseudo-articulation formation. There was no significant difference between the two groups regarding age, sex, preoperative diagnosis and the type of implant.

\section{Clinical Outcome}

There are no clear advantages in clinical outcome of dynamic plates over static plates (Table II). Neurological status of the patients was assessed using JOA scoring system. The average JOA score for both groups were increased compared to preoperative scores. The average JOA score for the dynamic group was $7.68 \pm 1.66$ and increased to $10.92 \pm 1.97$ after surgery $(p<0.05)$, which accounted for significant improvement of 3.74. The JOA score reached to $12.74 \pm 1.27$ at the end of follow-up period, which increased 5.06 scores $(p<0.05)$. For the static group, the average JOA score was $7.46 \pm 1.44$ and increased to $10.85 \pm 2.08$ after surgery $(p<0.05)$, which accounted for a significant increase of 3.39. The JOA score reached about $12.31 \pm 1.22$ at the end of follow-up period, which increased 4.85 scores $(p<0.05)$. There was no statistical difference between the groups regarding preoperative, postoperatively or final clinical status of the patients $(p>0.05)$. Both groups showed a significant improvement in neurological status when compared with the preoperative neurological status.

\section{Radiological Outcome}

Solid fusion situation: In the dynamic group, 18 (50\%) of the 36 patients achieved solid fusion at the $3^{\text {rd }}$ month after surgery, and $26(72.2 \%)$ patients achieved solid fusion at the $6^{\text {th }}$ month after surgery. In the static group, $14(41.1 \%)$ of the 19 patients achieved solid fusion at the $3^{\text {rd }}$ month after surgery, and $23(67.6 \%)$ patients achieved solid fusion at the $6^{\text {th }}$ month after surgery. All of $70(100 \%)$ patients achieved solid fusion within one year after surgery (Table III, Figures 3, 4). There was no difference between the two groups at the $3^{\text {rd }}, 6^{\text {th }}$, and $12^{\text {th }}$ month after surgery ( $p>0.05)$.

One patient in the dynamic group suffered chronic neck pain 6 months after surgery and CT scan showed that the adjacent level of surgery had undergone fusion. More of the patients who underwent ACCF surgery with Vectra-T plate, titanium mesh cage and bone graft, achieved earlier fusion than the patients in the static-plate group but there were no significant difference in fusion rate between the two groups.

Measurement of regional cervical angle: Radiological examinations revealed that the mean local cervical angle (angle between $a$ and $b$ in Figure 1) was -2.98 degrees (a negative value corresponds to a lordotic angle and a positive value indicates the presence of kyphosis) in the dynamic group and -3.57 degrees in the static group, compared to the preoperative measurements. There was a significant difference after the surgery $(p<0.05)$, but there was no significant difference between the two groups. The local cervical angle at the end of the follow-up period declined compared to the postoperative local cervical angle but improved compared to the preoperative measurements (Table IV, Figure 1).

Table II: JOA Score $\left(\bar{X}_{ \pm} S\right)$

\begin{tabular}{lccc}
\hline & $\begin{array}{c}\text { Before } \\
\text { surgery }\end{array}$ & After surgery & $\begin{array}{c}\text { Time of } \\
\text { follow up }\end{array}$ \\
\hline Dynamic & $7.46 \pm 1.44$ & $10.85 \pm 2.08$ & $12.31 \pm 1.22$ \\
\hline Static & $7.68 \pm 1.66$ & $10.92 \pm 1.97$ & $12.74 \pm 1.27$ \\
\hline
\end{tabular}

$p>0.05$ in all the time points.

Table III: Conditions of Fusion

\begin{tabular}{llll}
\hline & 3 months & $\mathbf{6}$ months & 12 months \\
\hline Static & $14(41.1 \%)$ & $23(67.6 \%)$ & $34(100 \%)$ \\
\hline Dynamic & $18(50 \%)$ & $26(72.2 \%)$ & $36(100 \%)$ \\
\hline
\end{tabular}

$p>0.05$ in all the time points.

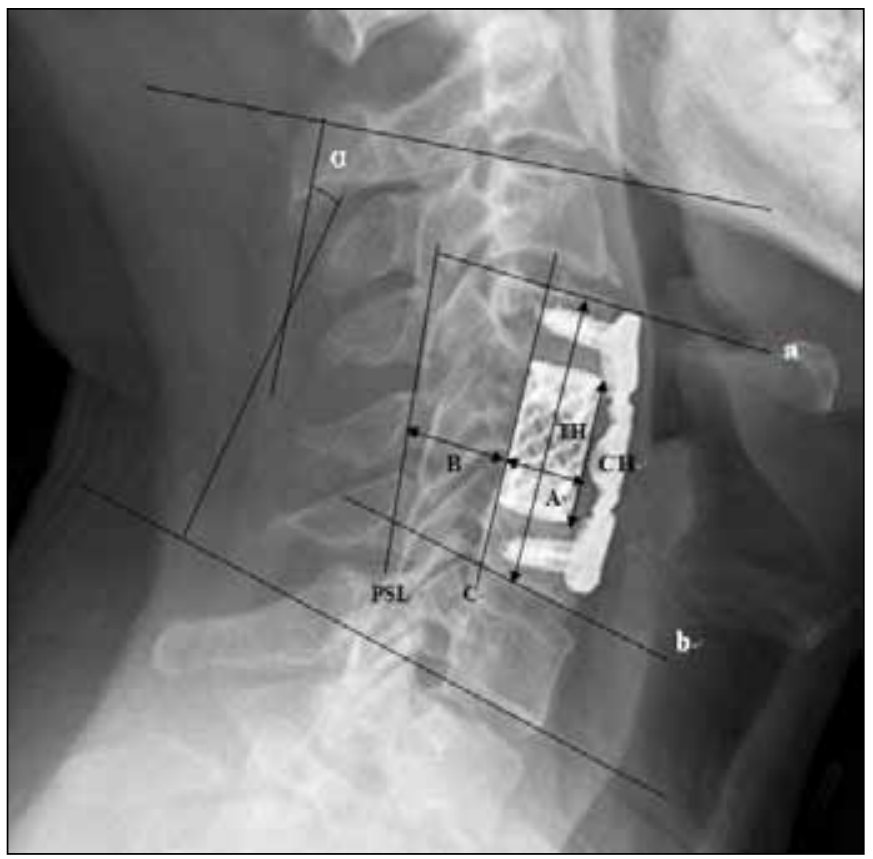

Figure 1: Lateral radiographs of a patient showing the parameters used for assessing outcome. Local cervical angle (angle between $a$ and b) and regional cervical angle (a). A negative value corresponds to a lordotic angle and a positive value indicates the presence of kyphosis. The settling ratio was defined as the quotient of the cage height $(\mathrm{CH})$ and the distance between the superior end of the superior vertebra and the inferior end of the inferior vertebra (TH). The sagittal displacement was defined as the quotient of the distance between the posterior margins of the cage and the posterior spinal line (PSL) (B) and cage width (A). The sagittal angle was defined as that subtended by the posterior edge of the cage and the posterior spinal line (C versus PSL). 


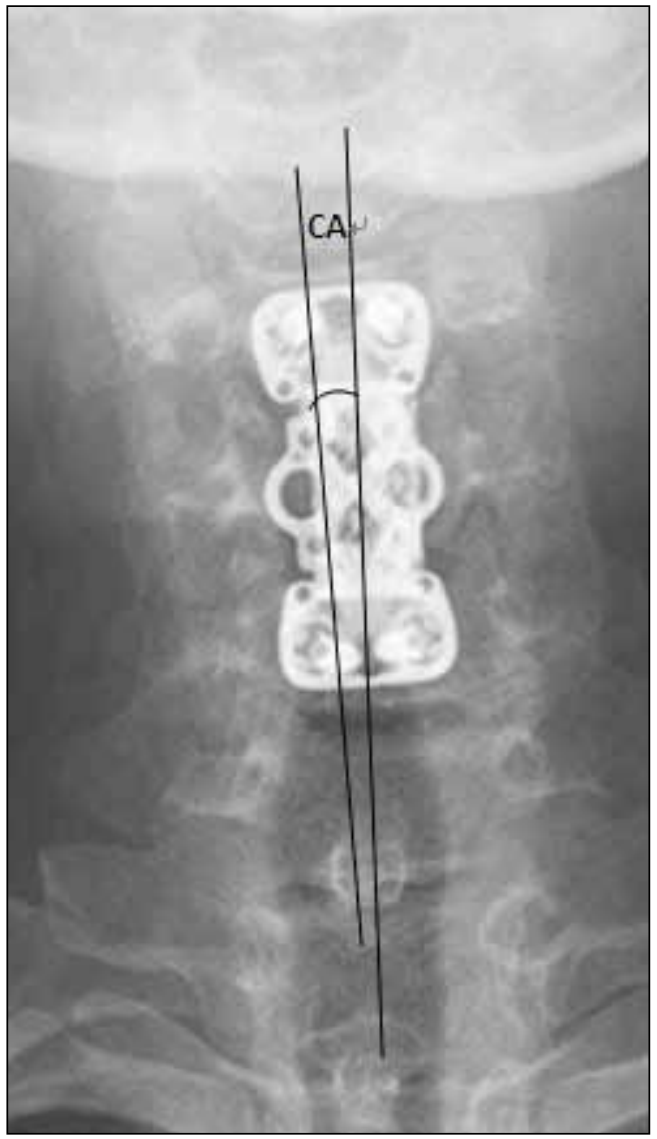

Figure 2: The coronal angle (CA) was defined as that subtended by the lateral margin of the plate and the spinous process line.
Radiological evaluations revealed that the mean regional cervical angle was -4.48 degrees (a negative value corresponds to a lordotic angle and a positive value indicates the presence of kyphosis) in the dynamic group and -3.25 degrees in the static group compared to the preoperative measurements. There was a significant difference after the surgery $(p<0.05)$, but there was still no significant difference between the two groups ( $\mathrm{p}>0.05)$.

Evaluation of stability: The sagittal angle was used to evaluate the morbidities of graft collapse, extrusion, or progressive kyphosis. In this study, no patients experienced a change in sagittal angle of more than $10^{\circ}$ in two groups, which indicated no significant instability, and there were no significant difference between the two groups.

The sagittal average angle of the two groups immediately after surgery was $2.31 \pm 1.32^{\circ}$ (dynamic-plate group) and $2.26 \pm 3.39^{\circ}$ (static-plate group). At the third month after surgery, it was $2.10 \pm 0.96^{\circ}$ and $2.21 \pm 2.42^{\circ}$; at the $6^{\text {th }}$ month after surgery, it was $2.46 \pm 1.15^{\circ}$ and $2.61 \pm 1.42^{\circ}$, at the $12^{\text {th }}$ it was $3.41 \pm 1.86^{\circ}$ and $3.18 \pm 1.57^{\circ}$, at the end of the followup period it was $2.71 \pm 1.24^{\circ}$ and $3.02 \pm 1.18^{\circ}$. The coronal angle was used to evaluate the radiographic stability. If the coronal angle changed more than $10^{\circ}$ at each time point, it was considered a significant instability. In this study, no patients experienced significant instability. The results of the coronal angle in the dynamic and static-plate groups were as follows for each time point: $1.55 \pm 0.35^{\circ}$ and $2.20 \pm 2.41^{\circ}$ (immediate postoperative), $2.70 \pm 1.77^{\circ}$ and $2.67 \pm 2.02^{\circ}\left(3^{\text {rd }}\right.$ month), $2.48 \pm 1.34^{\circ}$ and $2.61 \pm 1.76^{\circ}$ (6 $6^{\text {th }}$ month), $2.53 \pm 1.57^{\circ}$ and $3.20 \pm 2.47^{\circ}\left(12^{\text {th }}\right.$ month), $4.26 \pm 2.13^{\circ}$ and $4.25 \pm 2.95^{\circ}$ (End of the follow-up period). There was no significant difference

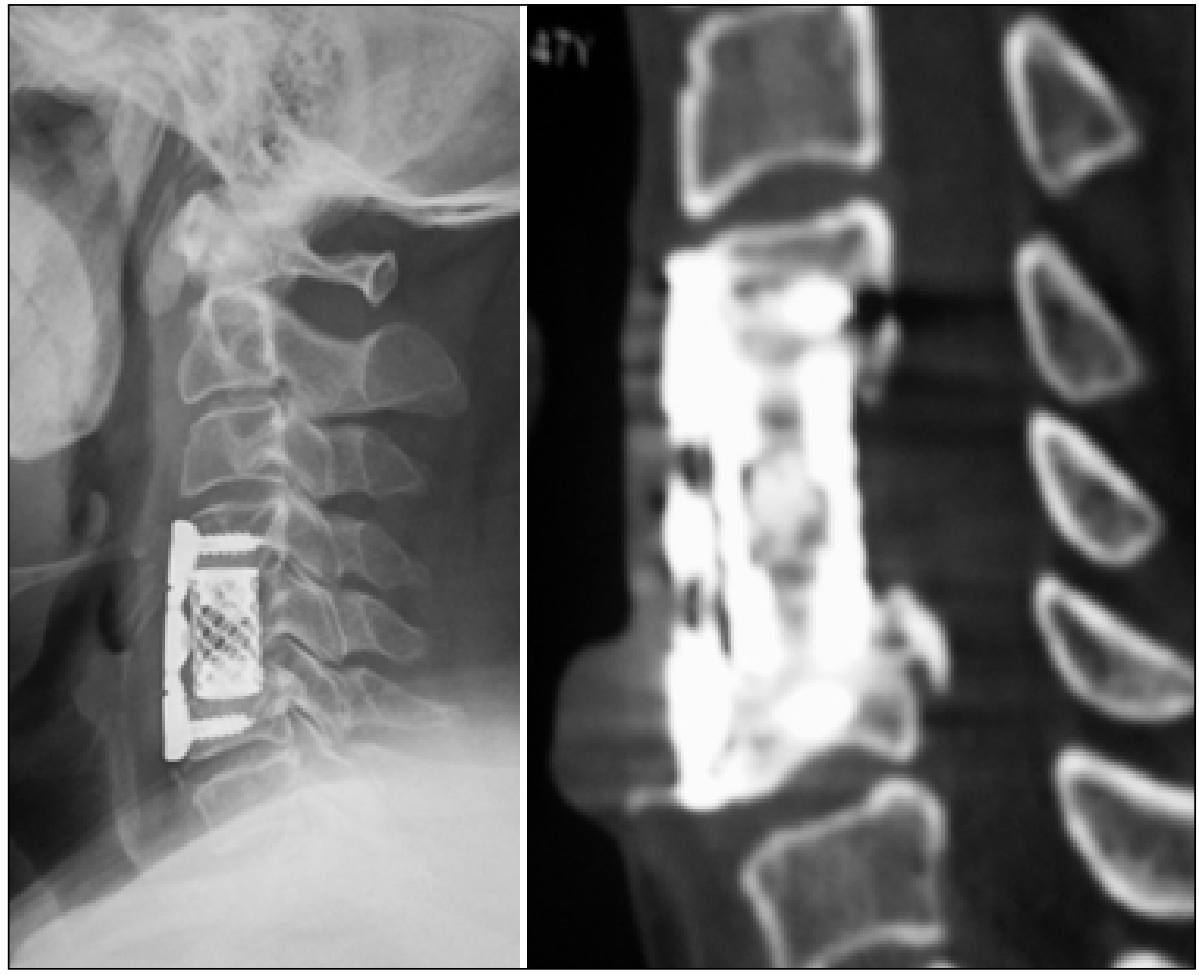

Figure 3: Sagittal X-rays and CT scan show the solid fusion. 

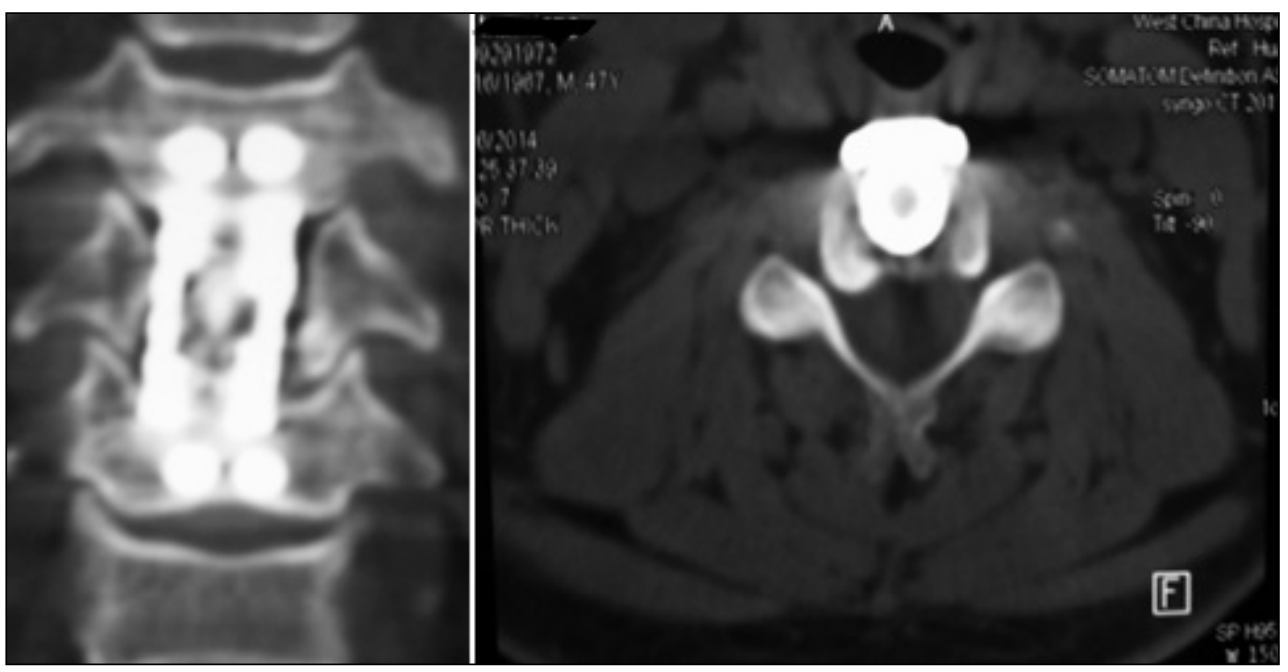

Figure 4: Coronal and axial CT scans show the solid fusion.

Table IV: Cervical Angle $\left(\bar{X}_{ \pm} S\right)$

\begin{tabular}{llccc}
\hline & & Before surgery & After surgery & Time of follow up \\
\hline \multirow{2}{*}{ Local cervical angle } & Static & $2.16 \pm 3.22$ & $5.73 \pm 5.94$ & $6.94 \pm 6.50$ \\
\cline { 2 - 5 } & Dynamic & $2.87 \pm 5.70$ & $5.85 \pm 6.19$ & $7.11 \pm 4.12$ \\
\hline \multirow{2}{*}{ Regional cervical angle } & Static & $11.2 \pm 0.83$ & $14.45 \pm 1.21$ & $12.72 \pm 1.04$ \\
\cline { 2 - 5 } & Dynamic & $10.3 \pm 5.13$ & $14.78 \pm 6.03$ & $12.55 \pm 35.1$ \\
\hline
\end{tabular}

Table V: Sagittal Plane Mobility and the Sedimentation Rate

\begin{tabular}{lcc}
\hline & \multicolumn{2}{c}{ Number } \\
\cline { 2 - 3 } & Static & Dynamic \\
\hline Sagittal plane mobility & & \\
\hline No change & 21 & 17 \\
\hline $\mathbf{1 - 4 ^ { \circ }}$ & 9 & 16 \\
\hline $\mathbf{5 - 9 ^ { \circ }}$ & 4 & 3 \\
\hline $\mathbf{1 0 ^ { \circ }}$ & 0 & 0 \\
\hline Sedimentation rate & & \\
\hline No change & 17 & 13 \\
\hline $\mathbf{1 - 4} \%$ & 11 & 17 \\
\hline $\mathbf{5 - 9} \%$ & 6 & 6 \\
\hline $\mathbf{1 0} \%$ & 0 & 0 \\
\hline
\end{tabular}

between the two groups ( $p>0.05$ ). There was a change of less than $10 \%$ in sagittal plane mobility and sedimentation rate, which demonstrated the stability of the implant (Tables V-VIII, Figures 1,2).

Displacement of implants and intervertebral disc involvement: During the follow-up period, displacement of the implant was observed in 2 patients in the static group and in one patient in the dynamic group and the displacement involved the intervertebral disc space. However, these patients did not have any symptoms related to displacement of the implant.

\section{DISCUSSION}

ACCF surgery is a common and successful method for the treatment of cervical degenerative disc disease. The anterior cervical plate has been developed as an adjunct to anterior bone grafting in order to prevent graft dislodgement, enhance the stability provided by the intervertebral bone graft, regain and keep physiological lordosis, and ultimately promote mature bony fusion of the spinal segment.

The design of the plates has been remarkably improved with the development of biomechanics. Dynamic anterior plates have been theoretically popularized to promote cervical spine fusion, but there were still some controversies in clinical outcomes compared to static plates (20).

Dynamic cervical plates have been introduced to reduce the stress shielding across the graft which may, in fact, affect graft healing by allowing for load sharing across the graft without apparent loss of rigidity $(2,9)$. These studies consequently confirmed the radiographic fusion rates. Some researchers suggested that the dynamic plates could provide a better effect in clinical use $(24-27,32)$. Goldberg et al. (16) observed a higher rate $(75 \%)$ of union 6 to 9 months after surgery in patients treated with a dynamic plate compared with a rate of $62.5 \%$ in patients treated with a static plate. In 10 to 13 months' follow-up, the union rate was $90 \%$ with a dynamic plate compared to $84.7 \%$ with a static plate. Nunley 
Table VI: Sagittal angle $\left(\bar{X}_{ \pm} S\right)$

\begin{tabular}{lcclcc}
\hline & After surgery & 3 months & 6 months & 12 months & Final follow-up \\
\hline Static & $2.26 \pm 3.39$ & $2.21 \pm 2.42$ & $2.61 \pm 1.42$ & $3.18 \pm 1.57$ & $3.02 \pm 1.18$ \\
\hline Dynamic & $2.31 \pm 1.32$ & $2.10 \pm 0.96$ & $2.46 \pm 1.15$ & $3.41 \pm 1.86$ & $2.71 \pm 1.24$ \\
\hline
\end{tabular}

Table VII: Coronal angle $\left(\bar{X}_{ \pm} S\right)$

\begin{tabular}{lccllc}
\hline & After surgery & $\mathbf{3}$ months & $\mathbf{6}$ months & \multicolumn{1}{c}{$\mathbf{1 2}$ months } & Final follow-up \\
\hline Static & $2.20 \pm 2.41$ & $2.67 \pm 2.02$ & $2.61 \pm 1.76$ & $3.20 \pm 2.47$ & $4.25 \pm 2.95$ \\
\hline Dynamic & $1.55 \pm 0.35$ & $2.70 \pm 1.77$ & $2.48 \pm 1.34$ & $2.53 \pm 1.57$ & $4.26 \pm 2.13$ \\
\hline
\end{tabular}

Table VIII: Change of Sagittal Angle and Coronal Angle

\begin{tabular}{lcc}
\hline & \multicolumn{2}{c}{ Number } \\
\cline { 2 - 3 } & Static & Dynamic \\
\hline Change of sagittal angle & & \\
\hline No change & 21 & 26 \\
\hline $\mathbf{1 - 4 ^ { \circ }}$ & 13 & 9 \\
\hline $\mathbf{5 - 9 ^ { \circ }}$ & 0 & 1 \\
\hline $\mathbf{1 1 0 ^ { \circ }}$ & 0 & 0 \\
\hline $\mathbf{C h a n g e}^{\circ}$ of coronal angle & & 22 \\
\hline $\mathbf{N o}$ change & 26 & 14 \\
\hline $\mathbf{1 - 4 ^ { \circ }}$ & 8 & 0 \\
\hline $\mathbf{5 - 9 ^ { \circ }}$ & 0 & 0 \\
\hline $\mathbf{1 1 0 ^ { \circ }}$ & 0 & \\
\hline
\end{tabular}

(24) completed a prospective randomized single-blind trial comparing the visual analogue scale (VAS) score and the neck disability index (NDI) score between the dynamic plate and the static plate and there was no significant difference in single level ACCF. In multi-level ACCF, the dynamic plate group had lower score in VAS and NDI evaluation than the static plate group. On the other hand, other researchers (4, 12) found that there was no significant difference in the speed of fusion and the clinical effects between the 2 groups. In our research, there was no difference based on the JOA score of the patients between the two groups, while the dynamic plate had higher speed of fusion in average than the static plate group.

ACCF surgery can reduce the loss of local lordosis and correct the kyphosis (33). Researchers have proven that the anterior cervical plate can improve the lordotic curve $(19,33)$. Radiological evaluations by Kanayama et al. revealed that the mean local lordosis was $5.0 \pm 6.9^{\circ}$ before surgery, $6.9 \pm 5.6^{\circ}$ right after the surgery and $5.0 \pm 4.7^{\circ}$ at the end of the follow-up period (18). Das et al. (10) performed a retrospective study in 38 patients who underwent ACCF with static plates; 30 (79\%) patients had lordosis and $6(16 \%)$ had kyphosis. Pitzen et al.
(27) performed a study to compare the clinical outcomes of patients who underwent ACCF with either dynamic plates or static plates and they found that the loss of anterior spinal column was more serious but the clinical effect was similar between the two groups. In our study, radiological evaluations revealed that the mean local cervical angle was -2.98 degrees in the dynamic group and -3.57 degrees in the static group compared to the preoperative measurements. There was a significant difference before and after the surgery $(p<0.05)$, but there was no significant difference between the two groups. The local cervical angle at the end of the follow-up period declined compared to the postoperative local cervical angle but improved compared to the preoperative measurement. Evaluations revealed that the mean regional cervical angle was -4.48 degrees in the dynamic group and -3.25 degrees in the static group compared to the preoperative measurements. There was a significant difference before and after surgery $(p<0.05)$, but there was still no significant difference between the two groups $(p>0.05)$.

We inserted a mesh cage in all cases after corpectomy instead of autologous iliac crest graft to expect the same effect in fusion. There were many complications related to the autologous iliac crest, for example pain in iliac sampling area, haematoma, nerve injury and risk of infection. So, we preferred the more suitable method, the mesh cage, after corpectomy. Many studies have focused on the stability of the mesh cage. Narotam et al. (23) shared their experience of anterior cervical fusion using titanium mesh and a static plate. The sedimentation rates due to titanium mesh were $4.46 \%, 3.89 \%$ and $4.35 \%$ in 3 months, 6 months and one year after surgery. The change of sagittal plane mobility was 3.9\% after one year's follow-up. At the end of follow-up period, the change of sagittal angle and coronal angle was $2.89^{\circ}$ and $2.09^{\circ}$. In our study, there was no statistically significant difference regarding to mean sagittal angle, coronal angle, sagittal plane mobility and sedimentation rate between the two groups ( $p>0.05$ ) for each time point. There was a change of less than $10^{\circ}$ in all angles for both groups. The rate of sagittal mobility, $4.30 \pm 5.81 \%$ (the dynamic plate group) and $3.60 \pm 6.31 \%$ (the static plate group), and the sedimentation rate was $4.67 \pm 3.30 \%$ in dynamic plate and $4.11 \pm 2.27 \%$ in static group. The change was less than $10 \%$, which demonstrated the stability of the implant. 
Many investigators have focused on the factors that can affect the subsidence behavior of titanium mesh, such as the cutting way, the management of adjacent endplate and so on (14). In our study, $16(80 \%)$ of the 20 patients who underwent ACCF with titanium mesh experienced subsidence of the cage. It is commonly thought that the incidence of cage subsidence is higher in older patients and in women, especially after menopause, because the bone quality of the vertebrae and the thickness of the endplates decrease in these patients (17).

Most of the subsidence seemed to occur by the similar mechanism into the caudal part of the vertebral bodies, followed by the plate or screw extrusions (11). It is probably due to the micromotion of screw that made it hard for the plate to maintain the height of the vertebral bodies (15). Theoretically, complications of subsidence are the loss of intervertebral disc height, kyphotic deformity, neurologic deterioration and the reduction of neural foramen volume. In clinical studies, mild subsidence did not produce significant clinical results (22).

There was no statistically significant difference between dynamic plates (Vectra-T, Synthes, Switzerland) and static plates regarding to the rate of fusion. This might be secondary to the use of mesh cage instead of a graft after corpectomy. The clinical and radiographic changes, such as local cervical angle, regional cervical angle, the stability of the mesh cage and the deflection of implant, were also similar between the two groups. All patients in both groups can experience good or excellent results if the correct indication and appropriate treatment were performed.

\section{CONCLUSION}

The decision to choose a specific cervical implant is difficult despite increasing biomechanical and clinical data. Design of the plate probably does affect surgical outcome; however, most clinical series do not have the power to discern the differences. More scientifically designed, prospective, randomized clinical trials are still needed. The most appropriate spinal implant remains case-based, patient-specific, and whether a static or dynamic implant. It is considered to be a surgeon preference rather than indicated on the basis of strong biomechanical or clinical data.

\section{- ACKNOWLEDGEMENT}

There is no conflict of interest with The Company Synthes and any other companies.

\section{REFERENCES}

1. Bailey RW, Badgley CE: Stabilization of the cervical spine by anterior fusion. J Bone Joint Surg 42(4):565-624, 1960

2. Beutler WJ, Clavenna AL, Gudipally M, Moldavsky M, Khalil S: A biomechanical evaluation of a spacer with integrated plate for treating adjacent-level disease in the subaxial cervical spine. Spine J 12(7): 585-589, 2012

3. Bohler J, Gaudernak T: Anterior plate stabilization for fracturedislocations of the lower cervical spine. J Trauma 20(3):203205,1980
4. Bose B: Anterior cervical arthrodesis using DOC dynamic stabilization implant for improvement in sagittal angulation and controlled settling. J Neurosurg Spine 98(1):8-13, 2003

5. Brodke DS, Gollogly S, Alexander Mohr R, Nguyen BK, Dailey AT, Bachus AK: Dynamic cervical plates: Biomechanical evaluation of load sharing and stiffness. Spine 26(12):13241329, 2001

6. Brodke DS, Klimo P Jr, Bachus KN, Braun JT, Dailey AT: Anterior cervical fixation: Analysis of load-sharing and stability with use of static and dynamic plates. J Bone Joint Surg 88(7): 1566-1573, 2006

7. Brodsky AE, Khalil MA, Sassard WR, Newman BP: Repair of symptomatic pseudarthrosis of anterior cervical fusion: Posterior versus anterior repair. Spine 17(10):1137-1143, 1992

8. Cloward RB: The anterior approach for removal of ruptured cervical disks. J Neurosurg 15(6):602-617, 1958

9. Connor DE Jr, Shamieh KS, Ogden AL, Mukherjee DP, Sin A, Nanda A: Biomechanical performance of rigid compared to dynamic anterior cervical plating: Analysis of adjacent upper and lower level compressive forces. J Clin Neurosci 2012

10. Das K, Couldwell WT, Sava G, Taddonio RF: Use of cylindrical titanium mesh and locking plates in anterior cervical fusion: Technical note. J Neurosurg Spine 94(1):174-178, 2001

11. Daubs MD: Early failures following cervical corpectomy reconstruction with titanium mesh cages and anterior plating. Spine 30(12):1402-1406, 2005

12. DuBois CM, Bolt PM, Todd AG, Gupta P, Wetzel FT, Phillips FM: Static versus dynamic plating for multilevel anterior cervical corpectomy and fusion. Spine J 7(2):188-193, 2007

13. Geisler FH, Caspar W, Pitzen T, Johnson TA: Reoperation in patients after anterior cervical plate stabilization in degenerative disease. Spine 23(8):911-920, 1998

14. Gercek E, Arlet V, Delisle J, Marchesi D: Subsidence of standalone cervical cages in anterior interbody fusion: Warning. Eur Spine J 12(5):513-516, 2003

15. Ghahreman A, Rao PJ, Ferch RD: Dynamic plates in anterior cervical fusion surgery: Graft settling and cervical alignment. Spine 34(15): 1567-1571, 2009

16. Goldberg G, Albert TJ, Vaccaro AR, Hilibrand AS, Anderson $\mathrm{DG}$, Wharton $\mathrm{N}$ : Short-term comparison of cervical fusion with static and dynamic plating using computerized motion analysis. Spine 32(13):E371-E375, 2007

17. Hasegawa K, Abe M, Washio T, Hara T: An experimental study on the interface strength between titanium mesh cage and vertebra in reference to vertebral bone mineral density. Spine 26(8):957-963, 2001

18. Kanayama M, Hashimoto $T$, Shigenobu $K$, Oha $F$, Ishida $T$, Yamane S: Pitfalls of anterior cervical fusion using titanium mesh and local autograft. J Spinal Disord Tech 16(6):513-518, 2003

19. Lee JY, Park MS, Moon SH, Shin JH, Kim SW, Kim YC, Lee SJ, Suh BK, Lee HM: Loss of lordosis and clinical outcomes after anterior cervical fusion with dynamic rotational plates. Yonsei Med J 54(3):726-731, 2013

20. Lee MJ, Bazaz R, Furey CG, Yoo J: Influence of anterior cervical plate design on dysphagia: A 2-year prospective longitudinal follow-up study. J Spinal Disord Tech 18(5):406409, 2005 
21. Mobbs RJ, Rao P, Chandran NK: Anterior cervical discectomy and fusion: Analysis of surgical outcome with and without plating. J Clin Neurosci 14(7):639-642, 2007

22. Nakase H, Park YS, Kimura H, Sakaki T, Morimoto T: Complications and long-term follow-up results in titanium mesh cage reconstruction after cervical corpectomy. J Spinal Disord Tech 19(5):353-357, 2006

23. Narotam PK, Pauley SM, McGinn GJ: Titanium mesh cages for cervical spine stabilization after corpectomy: A clinical and radiological study. J Neurosurg Spine 99(2):172-180, 2003

24. Nunley PD, Jawahar A, Kerr EJ 3rd, Cavanaugh DA, Howard C, Brandao SM: Choice of plate may affect outcomes for single versus multilevel ACDF: Results of a prospective randomized single-blind trial. Spine J 9(2):121-127, 2009

25. Okawa A, Sakai K, Hirai T, Kato T, Tomizawa S, Enomoto M, Kawabata S, Takahashi M, Shinomiya K: Risk factors for early reconstruction failure of multilevel cervical corpectomy with dynamic plate fixation. Spine 36(9): E582-E587, 2011

26. Orozco C, Llovet Tapies J: Osteosíntesis en las lesiones traumáticas y degenerativas de la columna cervical. Revista Traumatol Cirug Rehabil 1:45-72, 1971

27. Pitzen TR, Chrobok J, Stulik J, Ruffing S, Drumm J, Sova L, Kucera R, Vyskocil T, Steudel WI: Implant complications, fusion, loss of lordosis, and outcome after anterior cervical plating with dynamic or rigid plates: Two-year results of a multi-centric, randomized, controlled study. Spine 34(7):641646, 2009
28. Reidy D, Finkelstein J, Nagpurkar A, Mousavi P, Whyne C: Cervical spine loading characteristics in a cadaveric C5 corpectomy model using a static and dynamic plate. J Spinal Disord Tech 17(2):117-122, 2004

29. Robinson RA, Walker AE, Ferlic DC, Wiecking DK: The results of anterior interbody fusion of the cervical spine. J Bone Joint Surg 44(8):1569-1587, 1962

30. Samartzis D, Shen FH, Lyon C, Phillips M, Goldberg EJ, An HS: Does rigid instrumentation increase the fusion rate in onelevel anterior cervical discectomy and fusion? Spine J 4(6): 636-643, 2004

31. Smith GW, Robinson RA: The treatment of certain cervicalspine disorders by anterior removal of the intervertebral disc and interbody fusion. J Bone Joint Surg 40(3): 607-624, 1958

32. Stulik J, Pitzen TR, Chrobok J, Ruffing S, Drumm J, Sova L, Kucera R, Vyskocil T, Steudel WI: Fusion and failure following anterior cervical plating with dynamic or rigid plates: 6-months results of a multi-centric, prospective, randomized, controlled study. Eur Spine J 16(10):1689-1694, 2007

33. Troyanovich SJ, Stroink AR, Kattner KA, Dornan WA, Gubina I: Does anterior plating maintain cervical lordosis versus conventional fusion techniques? A retrospective analysis of patients receiving single-level fusions. J Spinal Disord Tech 15(1):69-74, 2002 